\title{
USING THERMOGRAVIMETRIC ANALYSIS TO MEASURE THE DRYING RATES OF INDIVIDUAL RICE KERNELS
}

\author{
M. A. Billiris, T. Thurow, T. J. Siebenmorgen
}

\begin{abstract}
Individual kernel drying rates could be used to better estimate intra-kernel MC and material state gradients, which in turn would help estimate the occurrence of kernel fissuring inside rice dryers. Drying curves of individual kernels were obtained using a thermogravimetric analyzer for three long-grain cultivars (Wells, CL XL745, and CL 142) and two medium-grain cultivars (CL 261 and Jupiter) at $40^{\circ} \mathrm{C}, 50^{\circ} \mathrm{C}$, and $60^{\circ} \mathrm{C}$. Drying rates of individual kernels were obtained from drying curves using a three-parameter, exponential decay model. Prior to drying experiments, kernel thickness, width and length of individual rough rice kernels were measured using a digital micrometer. Total lipid content, amylose content, protein content and initial moisture content were determined for each cultivar. In general, drying rate increased as kernel thickness decreased for both long-grain and medium-grain cultivars; this effect was more pronounced at $60^{\circ} \mathrm{C}$. Kernel width was also a factor that affected drying rates; as kernel width increased, drying rate increased.
\end{abstract}

Keywords. Drying curves, Individual rough rice kernels, Rice kernel dimensions.

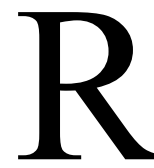
ough rice is typically harvested at a moisture content (MC) greater than the 12\%-13\% (moisture contents are expressed on a wet basis) level generally recommended for long-term storage, and thus must be dried to prevent deterioration (Fan et al., 2000; Cihan and Ece, 2001). Individual kernels interact with the drying medium through heat and mass transfer processes, and thus collectively determine the overall drying rate of bulk grain (Yang et al., 2003a). Most grain drying research has focused on the bulk drying behavior of grain, and much less on the drying behavior of individual kernels. Intra-kernel MC and material state profiles, which are determined in large part by the drying rate, greatly impact the development of fissures (Yang et al., 2003a; Schluterman and Siebenmorgen, 2007). Thus, research on the effects of factors that impact drying rates of individual kernels may help determine which kernels are more prone to fissuring and correspondingly, are responsible for reductions in milling yield. This is relevant given the economic importance of milling yield to the rice processing industry (Ondier et al., 2010).

Rough rice drying rates are influenced by drying air temperature $(\mathrm{T})$, relative humidity $(\mathrm{RH})$, and velocity, as well as initial kernel MC (Wang and Singh, 1978; Dung et al., 1980; Banaszek and Siebenmorgen, 1993; Iguaz et al., 2003; Chen

Submitted for review in January 2016 as manuscript number PRS 11740; approved for publication by the Processing Systems Community of ASABE in July 2016.

The authors are Maria Alejandra Billiris, Senior Researcher, Department of Research, Development and Innovation, Technological Laboratory of Uruguay, Montevideo, Uruguay; Taylor Thurow, Former Undergraduate Student, Department of Food Science, University of Arkansas, Fayetteville, Arkansas; Terry J. Siebenmorgen, ASABE Fellow, University Professor, Department of Food Science, University of Arkansas, Fayetteville, Arkansas. Corresponding author: Terry J. Siebenmorgen, 2650 N. Young Ave, Fayetteville, AR 72704; phone: 479575-2841; e-mail: tsiebenm@uark.edu. and $\mathrm{Wu}, 2001)$. Several studies have also found drying rates to vary with rice type and associated kernel geometries. Bautista and Bekki (1997), and later Ondier et al. (2010), found that drying rates of long-grain cultivars were approximately three times greater than those of medium-grain cultivars under the same drying conditions. Additionally, Dong et al. (2009) reported that the drying constant of a long-grain cultivar was significantly greater than that of a short-grain cultivar, at all drying air conditions tested $\left(30^{\circ} \mathrm{C}-50^{\circ} \mathrm{C}, 60 \%\right.$ $\mathrm{RH}, 0.5 \mathrm{~m} / \mathrm{s}$ air flow). Even within a rice type, drying behavior can be different among cultivars. For example, Banaszek and Siebenmorgen (1993) found significant differences in the drying constants of two long-grain cultivars.

Several studies have concluded that of all factors, drying air T had the greatest effect on drying rate (Dung et al., 1980; Bautista and Bekki, 1997; Iguaz et al., 2003; Kahveci et al., 2003). Ondier et al. (2010) conducted a thin-layer drying experiment at low temperatures $\left(26^{\circ} \mathrm{C}-34^{\circ} \mathrm{C}\right)$ using long- and medium-grain cultivars and found that increasing the drying air temperature increased the drying rate and decreased the drying duration to reach $12.5 \%$ MC. Iguaz et al. (2003) found similar results when drying medium-grain rough rice in a thin layer; medium-grain rice dried using an air flow rate of $2.5 \mathrm{~m} / \mathrm{s}$ dried 2.7 times faster at $35^{\circ} \mathrm{C}$ than at $5^{\circ} \mathrm{C}$. In addition, Dong et al. (2009) conducted a thin-layer drying experiment using temperatures ranging from $30^{\circ} \mathrm{C}$ to $50^{\circ} \mathrm{C}$; the drying rate increased with increasing $\mathrm{T}$ for both long- and short-grain rough rice. Madhava et al. (2001) used a thermogravimetric analyzer (TGA) to dry individual kernels of medium-grain rough rice at temperatures ranging from $40^{\circ} \mathrm{C}$ to $60^{\circ} \mathrm{C}$; after 50 min of drying, a $10 \%$ mass loss was achieved at $60^{\circ} \mathrm{C}$ while only approximately $5 \%$ was achieved at $40^{\circ} \mathrm{C}$.

Banaszek and Siebenmorgen (1993) found that there were differences among the drying rates and equilibrium moisture contents (EMCs) of individual kernels of rough rice within the same cultivar sample. The authors explained 
that this could be due to physical and hygroscopic differences among kernels; a regression analysis showed that the drying rate was affected by the initial $\mathrm{MC}$ and the ratio of kernel width to thickness. Bautista and Bekki (1997) stated that bolder rice kernels, such as medium-grain cultivars, have lesser length-to-width ratios than slender kernels; greater diffusion pathways are associated with such geometries and thus, a longer duration is required for water to migrate from the core of the kernel to the surface.

Several studies have reported that milling yield is affected by kernel dimensions. For example, Fan et al. (2000) reported that a medium-grain cultivar incurred greater milling quality reduction than two long-grain cultivars at any given drying condition and duration; the authors explained that the differences in milling yield reduction among cultivars could be partially due to differences in harvest MC, but they also attributed the reductions to differences in kernel dimensions, stating that shorter, thicker kernels are more vulnerable to fissuring than longer, more slender kernels. Additionally, Yang et al. (2003a) and Yang et al. (2003b) reported that MC gradients, which are of importance in the formation of fissures (Schluterman and Siebenmorgen, 2007), form along the short axis of a kernel, which was considered to be the average of a kernel's width and thickness. Thus, differences in kernel dimensions would impact the formation of these gradients.

Since differences in drying rates have been shown to exist between individual rough rice kernels, it can be hypothesized that the overall drying rate of rice could be more accurately predicted if the drying behavior of individual kernels was taken into consideration when developing mathematical models for describing the drying process inside dryers. Further, individual kernel drying rates could be used to better estimate intra-kernel $\mathrm{MC}$ and material state gradients (Cnossen and Siebenmorgen, 2000; Siebenmoregn et al., 2004), which in turn would help estimate the occurrence of kernel fissuring. The objectives of this experiment were to: (1) quantify drying rates for single, rough rice kernels from various long- and medium-grain cultivars using a TGA, and (2) relate kernel dimensions to drying characteristics at various $\mathrm{T}$ levels.

\section{MATERIALS AND MeTHODS}

Two pureline medium-grain cultivars (CL 261 and Jupiter), two pureline long-grain cultivars (CL 142 and Wells) and one hybrid long-grain cultivar (CL XL745) were harvested from the Northeast Research and Extension Center near Keiser, Arkansas in October, 2011. Lots ranged in MC from $17.7 \%$ to $21.6 \%$. After harvest, the lots were transported to the University of Arkansas Rice Processing Program Laboratory (Fayetteville, Ark.), cleaned with a dockage tester (model XT4, Carter Day Co., Minneapolis, Minn.) and then stored in sealed; $68 \mathrm{~L}$ (18-gal) bins at $4 \pm 1{ }^{\circ} \mathrm{C}$ until drying experiments commenced.

\section{Proximate Composition and Kernel Dimensions}

Prior to drying experiments proximate composition [total lipid content (TLC), amylose content (AC), protein content, and initial moisture content (IMC)] of the bulk lots were de- termined. Before measuring proximate composition, sub-samples of each cultivar lot were dried in a T- and humidity-controlled chamber (AA5582, Parameter Generation \& Control, Black Mountain, N.C.) maintained at $26^{\circ} \mathrm{C}$ and $56 \%$ relative humidity, corresponding to a rough rice EMC of $11.5 \%$ (Chung-Pfost equation; ASABE Standards, 2009). Dried rough rice MCs were approximately $12.5 \%$; MC was determined using a convection oven in which duplicate, 15 -g samples were dried at $130^{\circ} \mathrm{C}$ for $24 \mathrm{~h}$ (Jindal and Siebenmorgen, 1987).

To determine TLC, $100 \mathrm{~g}$ of rough rice from each cultivar lot was dehulled in a laboratory sheller (THU, Satake, Tokyo, Japan), with a clearance of $0.048 \mathrm{~cm}$ between rollers, to produce brown rice. Any kernels with hulls still present were manually removed before measuring TLC. A cyclonic sample mill (3010-30, UDY, Fort Collins, Colo.) fitted with a 100 -mesh $(0.5 \mathrm{~mm})$ screen was used to grind the brown rice into flour. Brown rice TLC was determined in duplicate with a lipid extraction system (Avanti 2055, Foss North America, Eden Prairie, Minn.) according to AACCI Method 30-20.01 (AACCI, 2010), with modifications to the petroleum ether washing duration, as described by Matsler and Siebenmorgen (2005). TLC was defined as the mass of extracted lipid relative to the original brown rice mass, and expressed as a percentage.

To determine AC, duplicate samples of the rice flour were prepared for each cultivar lot. To obtain head rice, duplicate 150 -g rough rice samples were dehulled as described above and then milled for $30 \mathrm{~s}$ with a laboratory mill (McGill No. 2, RAPSCO, Brookshire, Tex.). Head rice was separated from broken kernels with a sizing device (Seedburo Equipment, Chicago, Ill.). Twenty grams of head rice from each lot was then ground into flour with the cyclonic sample mill previously described. Apparent AC was determined by the method of Williams et al. (1958), adapted for use with an automatic analyzer (AutoAnalyzer 3, Seal Analytical, Mequon, Wis.) using a wavelength of $620 \mathrm{~nm}$ (Juliano, 1971). The resulting average absorbance values were plotted against a prepared standard curve of known amylose percentages and the $\mathrm{AC}$ of each sample was estimated from the equation associated with the standard curve.

To determine protein content, approximately $60 \mathrm{~g}$ of head rice from the milled samples were scanned using a diode array analyzer (DA7200, Perten Instruments, Huddinge, Sweden) using a $75-\mathrm{mm}$ diameter holder that rotated during nearinfrared spectroscopy scanning. Two scans were conducted on each sample and averaged for data analysis. The diode array analyzer was calibrated against the standard Kjeldahl method (AOAC, 1990).

Initial moisture content of each lot was determined by an air oven method in which duplicate, 15 -g samples were placed in a convection oven at $130^{\circ} \mathrm{C}$ for $24 \mathrm{~h}$ (Jindal and Siebenmorgen, 1987).

To determine average kernel dimensions of the dried subsamples, 300 rough rice kernels from each cultivar lot were analyzed with an image analysis system (Satake Rice Image Analyzer-1A, Satake Co., Japan). Individual kernel dimensions used for the drying analyses were taken on non-dried kernels; that procedure is described below. Table 1 shows the proximate composition and kernel dimensions of the lots. 


\section{DRYING EXPERIMENTS}

Rough rice kernels were individually dried at temperatures of $40^{\circ} \mathrm{C}, 50^{\circ} \mathrm{C}$, or $60^{\circ} \mathrm{C}$. Before a drying run was conducted, $50 \mathrm{~g}$ of rough rice representing approximately 1,000 kernels, from a given cultivar lot was spread in a thin layer to allow temperature equilibration and placed in doublesealed Ziploc plastic bags and allowed to equilibrate to room temperature $\left(\sim 20^{\circ} \mathrm{C}\right)$ for an hour. For each drying run, a 30-kernel set was selected from the 50-g sample and used for the individual-kernel drying runs. These 30 kernels comprised seven thick kernels and seven thin kernels: thin and thick kernels were selected after visual inspection. To corroborate that the thin and thick kernels picked were actually extreme kernels, 300-kernel distributions, obtained using the image analyzer described above, were used. Additionally, 16 kernels were randomly selected. Prior to drying, the length, width, and thickness of each kernel were measured with a digital micrometer (Absolute Digimatic Caliper, Miutoyo Corp., Japan), which allowed assessing the effect of kernel dimensions on dying rates.

Drying experiments were carried out using a thermogravimetric analyzer (TGA Q50, TA Instruments, New Castle, Del.), with a weighing system accuracy of $0.001 \mathrm{mg}$. During a drying run, an individual rice kernel was placed on a platinum sample pan and loaded in the TGA. Initially, samples were heated at a rate of $25^{\circ} \mathrm{C} / \mathrm{min}$ from approximately $20^{\circ} \mathrm{C}$ to the selected drying conditions of 40,50 , or $60^{\circ} \mathrm{C}$ using a constant $\mathrm{N}_{2}$ flow rate of $80 \mathrm{~mL} / \mathrm{min}$. Samples were then dried isothermally at either $40^{\circ} \mathrm{C}$ for $120 \mathrm{~min}, 50^{\circ} \mathrm{C}$ for $80 \mathrm{~min}$, or $60^{\circ} \mathrm{C}$ for $50 \mathrm{~min}$. These durations were selected based on preliminary runs, in which the minimum duration required to attain equilibrium was determined. The mass of the kernel being dried was measured continuously throughout the drying run. At the termination of the run, the kernel was removed from the TGA and its final MC was determined by drying in a convection oven maintained at $130^{\circ} \mathrm{C}$ for $24 \mathrm{~h}$ as previously described. Knowing the final $\mathrm{MC}$ and the masses taken during drying, the IMC of each individual kernel was calculated.

Drying curves of individual kernels were obtained using TGA software (Universal Analysis 2000, TA Instruments, New Castle, Del.). To determine the drying rate of individual kernels under the various drying scenarios, drying curves of each kernel were described using a three-parameter, exponential-decay model (eq. 1) available in the non-linear regression platform in JMP Pro software (SAS Institute Inc., Cary, N.C.). Constants $\mathrm{a}, \mathrm{b}$, and $\mathrm{k}$ were determined through a series of iterative steps for each kernel.

$$
M C=\mathrm{a}+\mathrm{b} \cdot \exp (-\mathrm{k} \cdot d)
$$

where

$\mathrm{MC}=$ the moisture content of the kernel at a given duration, dry basis (\%),

a = the EMC asymptote, dry basis (\%),

$\mathrm{b}=$ the scale (i.e. the difference between the IMC and the EMC), percentage points,

$\mathrm{k}=$ the drying rate in $\mathrm{min}^{-1}$,

$\mathrm{d}=$ the drying duration in min.

JMP software was used to perform multiple linear regression analyses in order to assess the effect of experimental variables, which included rice cultivar/type, kernel length, width and thickness, and drying temperature on drying rates.

\section{RESULTS AND DISCUSSION}

Equation 1 was used to describe MC as a function of drying duration and to obtain the drying rate $(\mathrm{k})$ for each individual rice kernel tested. Figure 1 shows $\mathrm{MC}$ as a function of drying duration (drying curves) for 30 individual kernels of long-grain CL XL745 dried at $50^{\circ} \mathrm{C}$. As indicated by the varying shape of the drying curves in figure $1, \mathrm{k}$ varied considerably among individual kernels For 30 individual kernels of CL XL745, k ranged from 0.006 to $0.045 \mathrm{~min}^{-1}$, from 0.016 to $0.068 \mathrm{~min}^{-1}$ (fig. 1), and from 0.037 to $0.15 \mathrm{~min}^{-1}$, respectively at drying temperatures of $40^{\circ} \mathrm{C}, 50^{\circ} \mathrm{C}$, and $60^{\circ} \mathrm{C}$. Similar trends were observed for the other cultivars studied.

\section{EFFECT OF KERNEL DIMENSIONS ON DRYING RATES OF INDIVIDUAL KERNELS}

Since drying rate was reasoned to be affected by several factors simultaneously, regression analysis was used to describe drying rate as a function of kernel thickness, width and length, as well as drying air temperature. The ratios of kernel length to width and width to thickness were also included as independent variables in the regression analysis. These ratios were included in the analysis to characterize the shape of the rice kernel, which has been reported to play a role in determining drying rates (Banaszek and\& Siebenmorgen, 1993). The equations and statistically-significant constants obtained from the regression analysis are shown below for long-grain (eq. 2) and medium-grain (eq. 3) cultivars. The $\mathrm{R}_{\mathrm{adj}}{ }^{2}$ and root mean square error (RMSE) were used to assess the appropriateness of the equations developed.

Long-grain cultivars:

$$
\begin{aligned}
k & =\mathrm{d}\left(T^{2}\right)+\mathrm{e}\left(t h^{2}\right)+\mathrm{f}(T)+\mathrm{g}(t h)+\mathrm{h}(W)+\mathrm{i}\left(\frac{L}{W}\right) \\
& +\mathrm{j}(t h)(T)+\mathrm{y}
\end{aligned}
$$

\begin{tabular}{|c|c|c|c|c|c|c|c|}
\hline Cultivar & $\begin{array}{l}\text { TLC } \\
(\%) \\
\end{array}$ & $\begin{array}{c}\text { Amylose } \\
(\%)\end{array}$ & $\begin{array}{c}\text { Protein } \\
(\%)\end{array}$ & $\begin{array}{c}\text { IMC } \\
\text { (\% w.b.) }\end{array}$ & $\begin{array}{c}\text { Length } \\
(\mathrm{mm})\end{array}$ & $\begin{array}{l}\text { Width } \\
(\mathrm{mm})\end{array}$ & $\begin{array}{c}\text { Thickness } \\
(\mathrm{mm})\end{array}$ \\
\hline Wells & 2.2 & 24.5 & 8.01 & 19.3 & 9.10 & 2.62 & 1.80 \\
\hline CLXL745 & 2.3 & 23.2 & 8.46 & 21.0 & 9.21 & 2.73 & 1.84 \\
\hline CL 142 & 2.6 & 24.8 & 8.97 & 19.0 & 8.76 & 2.68 & 1.79 \\
\hline CL 261 & 2.2 & 16.1 & 8.04 & & & & \\
\hline Jupiter & 2.5 & 14.2 & 7.70 & 18.4 & 7.86 & 3.13 & 1.87 \\
\hline
\end{tabular}

Table 1. Total lipid content (TLC), amylose content, protein content, initial moisture content (IMC) and average rough rice kernel dimensions of 300 kernels taken from cultivar-lot subsamples dried to approach $12.5 \%$. 


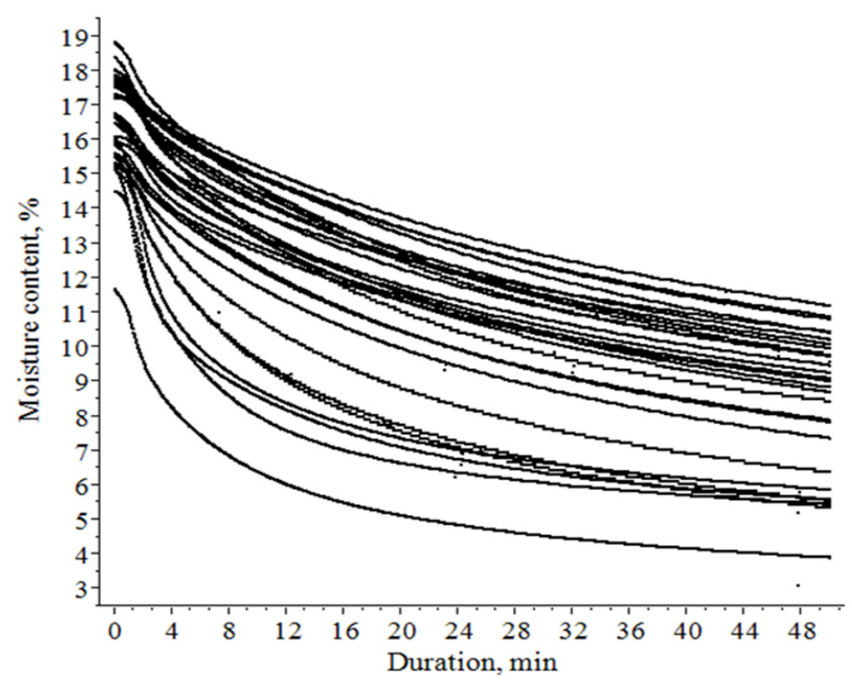

Figure 1. Drying curves of 30 individual kernels of long-grain $C L$ XL745 dried at $50^{\circ} \mathrm{C}$ in a thermogravimetric analyzer.

$$
\begin{aligned}
\mathrm{R}_{\mathrm{adj}}^{2} & =0.90 \mathrm{RMSE}=8.3 \mathrm{E}-3 \\
\mathrm{~d} & =6.9 \mathrm{E}-5 \\
\mathrm{e} & =4.7 \mathrm{E}-2 \\
\mathrm{f} & =4.5 \mathrm{E}-4 \\
\mathrm{~g} & =-5.5 \mathrm{E}-2 \\
\mathrm{~h} & =1.4 \mathrm{E}-2 \\
\mathrm{i} & =5.3 \mathrm{E}-3 \\
\mathrm{j} & =-2.9 \mathrm{E}-3 \\
\mathrm{y} & =-1.7 \mathrm{E}-2
\end{aligned}
$$

Medium-grain cultivars:

$$
k=\mathrm{d}\left(T^{2}\right)+\mathrm{f}(T)+\mathrm{g}(t h)+\mathrm{h}(W)+\mathrm{j}(t h)(T)+\mathrm{y}
$$

$$
\begin{aligned}
\mathrm{R}_{\mathrm{adj}}{ }^{2} & =0.76 \mathrm{RMSE}=1.3 \mathrm{E}-2 \\
\mathrm{~d} & =9.7 \mathrm{E}-5 \\
\mathrm{f} & =-1.9 \mathrm{E}-3 \\
\mathrm{~g} & =1.1 \mathrm{E}-1 \\
\mathrm{~h} & =1.5 \mathrm{E}-2 \\
\mathrm{j} & =3.1 \mathrm{E}-3 \\
\mathrm{y} & =-8.0 \mathrm{E}-2 \\
\mathrm{k} & =\text { drying rate }\left(\text { min }^{-1}\right) \\
\mathrm{T} & =\text { drying air temperature }\left({ }^{\circ} \mathrm{C}\right) \\
\mathrm{th} & =\text { kernel thickness }(\mathrm{mm}) \\
\mathrm{W} & =\text { kernel width }(\mathrm{mm})
\end{aligned}
$$

$\mathrm{L} / \mathrm{W}=$ the ratio of kernel length to width (dimensionless)

Equations 2 and 3 indicate that drying air T, kernel thickness and width were important factors affecting the drying rates of individual kernels for both long-grain and mediumgrain cultivars. The squared term for thickness was significant for long-grain cultivars (eq. 2), but not for mediumgrains (eq. 3), showing that the impact of thickness on drying rates was relatively more important for long-grain cultivars. Several researchers have reported that kernel dimensions play an important role in drying rates of rice kernels. For instance, Banaszek and Siebenmorgen (1993) reported that drying rates of individual kernels of long-grain cultivars Alan and Newbonnet were affected by the ratio of kernel width to kernel thickness. In the present study, the ratio of kernel length to width was significant for long-grain cultivars. It is noted that in both studies, length was only significant as a part of a ratio. Additionally, it is well established that drying air $\mathrm{T}$ is a major factor affecting drying rates (Dung et al., 1980; Bautista and Bekki, 1997; Iguaz et al., 2003; Kahveci et al., 2003). It was observed that the squared term for drying air $\mathrm{T}$ was significant in both equations, demonstrating the importance of this factor for both longgrain and medium-grain cultivars. Finally, equations 2 and 3 indicate that there was a significant interaction between kernel thickness and drying air $\mathrm{T}$.

Figures $2 \mathrm{a}, 2 \mathrm{~b}$, and $2 \mathrm{c}$ show drying rates of individual kernels as a function of kernel thickness at $40^{\circ} \mathrm{C}, 50^{\circ} \mathrm{C}$, and $60^{\circ} \mathrm{C}$ for long-grains Wells, CL XL745 and CL 142, respectively. Each data point represents the drying rate of one of the 30 individual kernels tested for a given cultivar/drying $\mathrm{T}$ combination. In general, drying rate decreased as kernel thickness increased for all Ts. This is reasonable since the thicker the kernel, the greater the distance water needs to migrate from the center to the surface of the kernel, and thus the slower the kernel will dry. Figure 2 also shows that the effect of kernel thickness on drying rate became more pronounced as $\mathrm{T}$ increased, reflecting the significant interaction between kernel thickness and drying $\mathrm{T}$ indicated in equation. This interaction is reasoned to be manifested in terms of both the diffusivity of kernel components and the drying rate at the kernel surface. At low Ts, water-removal rate at the surface of the kernel is low and thus, the water-removal rate at the surface becomes the limiting factor affecting drying rates. Under these circumstances, the rate at which water migrates from the center to the surface may not have an impact on drying rate. Therefore, factors affecting the rate at which water migrates to the surface of the kernel, such as thickness (the thicker the kernel the greater the distance water needs to migrate to reach the surface), become less important when drying at low Ts. Conversely, at higher Ts, water-removal rate at the surface of the kernel might be sufficiently great so as to cause the limiting factor affecting drying rate to be the rate at which water migrates to the surface and thus, kernel thickness becomes a relatively more important factor affecting drying rates. Additionally, water diffusivity inside the kernel increases as $\mathrm{T}$ increases, which may also contribute to the trends observed in figure 2 (Prakash et al., 2011). The importance of both T and kernel thickness are reflected by the quadratic relationships of those factors in equation 2 .

Regarding the effect of kernel thickness on drying rates for medium-grain cultivars (fig. 3), the trends were similar to those observed for long-grains. It is noted that the effect of thickness on drying rate was always linear, even at $60^{\circ} \mathrm{C}$ (fig. 3).

Equation 3 was used to generate figures $4 \mathrm{a}$ and $4 \mathrm{~b}$, which show drying rate as a function of kernel thickness for a drying $\mathrm{T}$ of $50^{\circ} \mathrm{C}$ and at kernel widths of $2.9,3.1$, and $3.3 \mathrm{~mm}$ for medium-grain cultivars, CL 261 and Jupiter, respectively. Figure 4 indicates that drying rate increased as kernel width increased for both medium-grain cultivars. Similar trends were observed for long-grains. It was reasoned that as kernel width increased, surface area increased, which in turn 
(a)

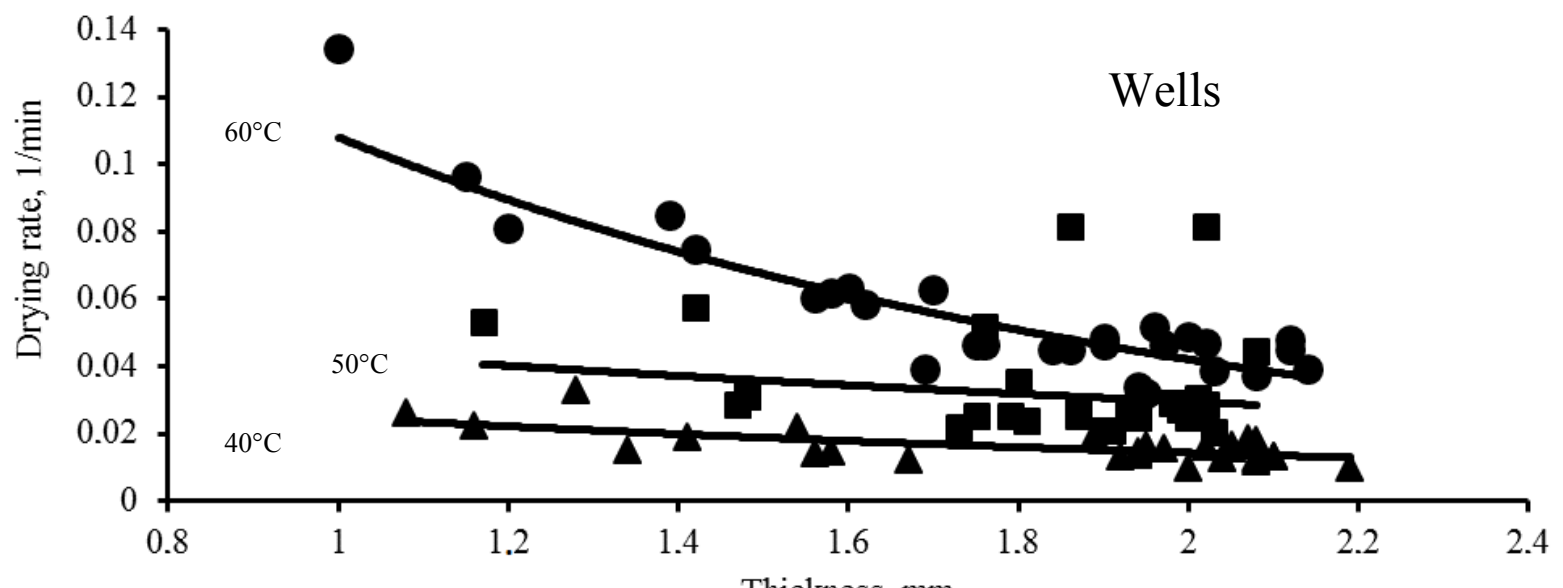

Thickness, mm

(b)

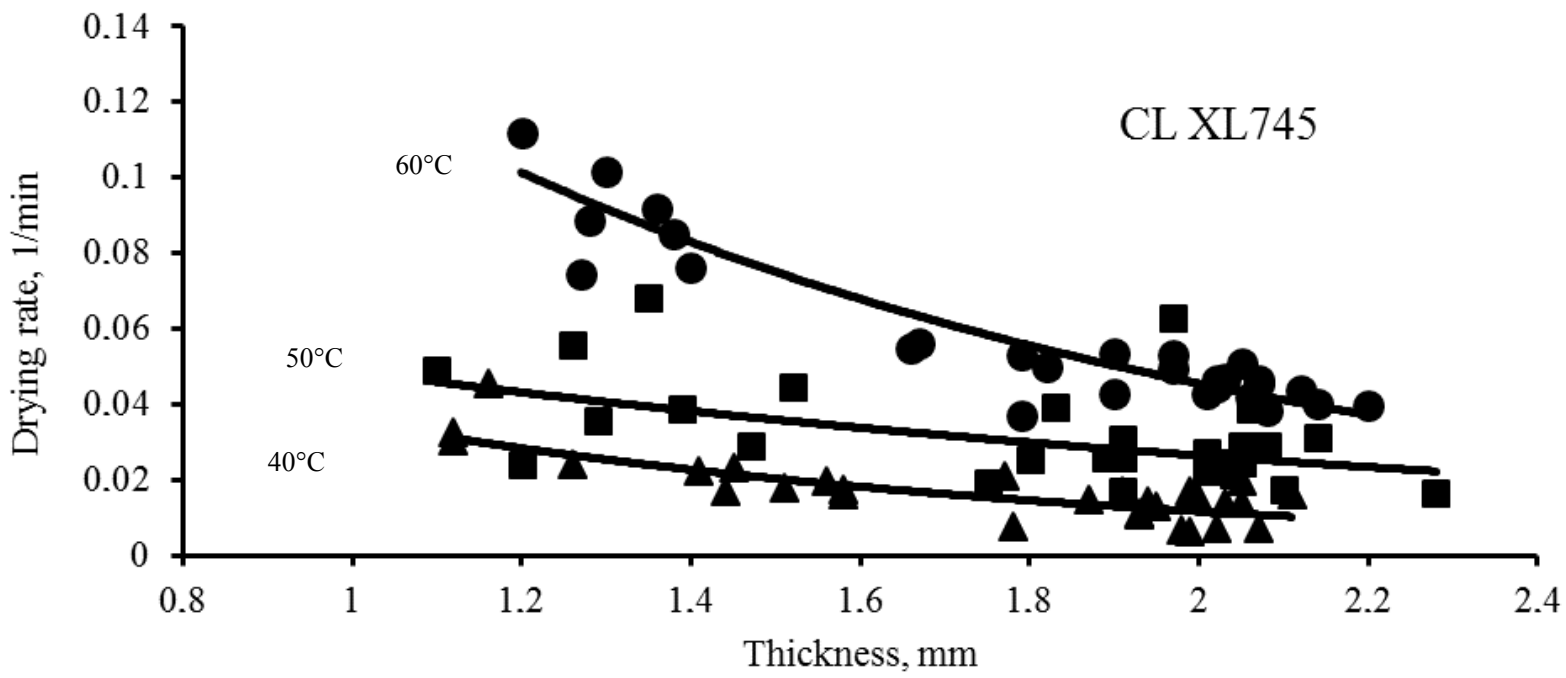

(c)

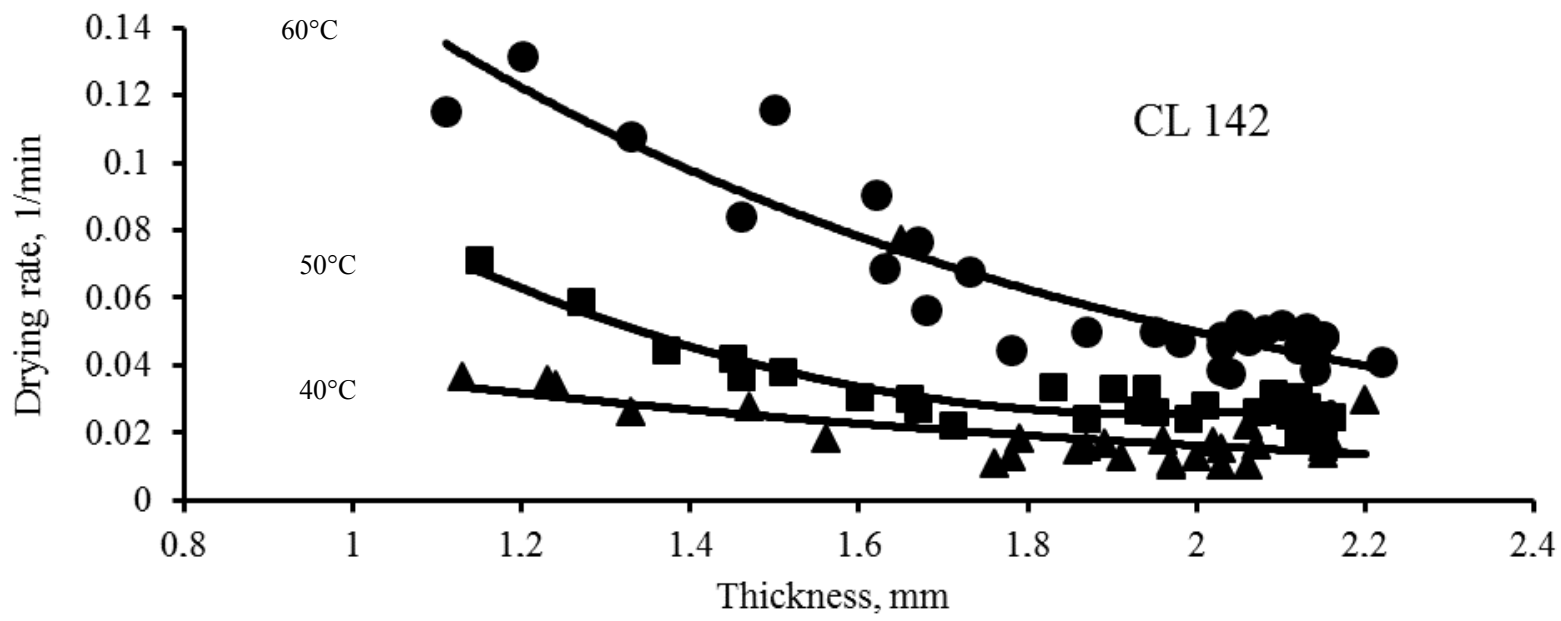

Figure 2. Drying rate (k, eq. 1) as a function of kernel thickness at $40^{\circ} \mathrm{C}, 50^{\circ} \mathrm{C}$, and $60^{\circ} \mathrm{C}$ for long-grain cultivars, Wells (a), CL XL745 (b), and CL 142 (c). Each data point represents the drying rate of an individual rough rice kernel plotted against the corresponding kernel thickness when dried at the specified temperature.

increased drying rate. There was no interaction between kernel width and drying air $\mathrm{T}$.

It is noted that at high Ts, the most important factor that affected drying rates of individual kernels was kernel thickness for both long-grain and medium-grain cultivars. It is hypothesized that since the thickness dimension represents the shortest kernel core-to-surface pathway, water migration in the thickness direction of the rice kernel is faster than that in the width direction and; thus, thickness becomes the most important dimension affecting drying rate. The findings of Wu et al. (2004) may support this hypothesis since the authors reported that the maximum MC gradient along the thickness direction was almost twice that in the direction of 
(a)
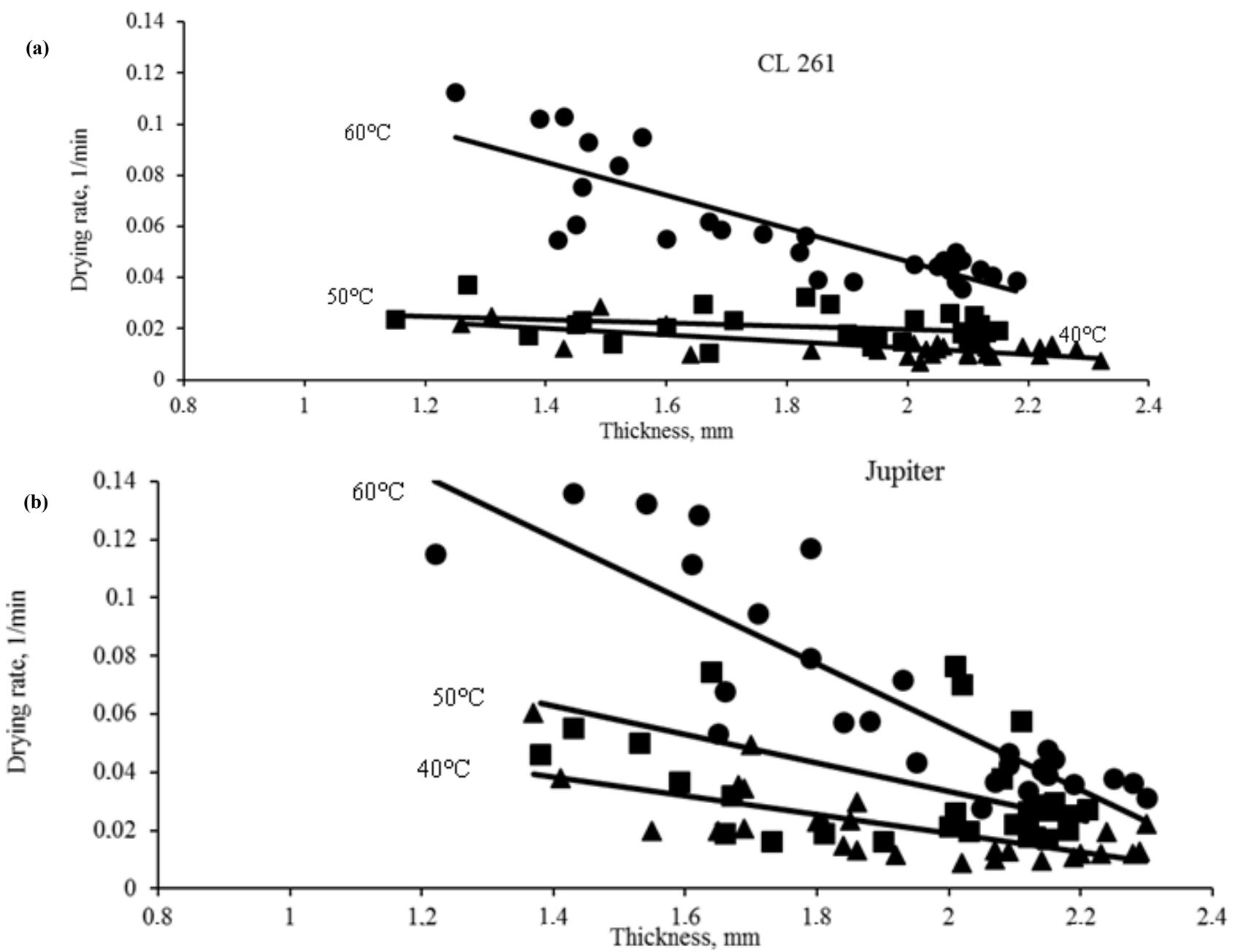

Figure 3. Drying rate (k, eq. 1) as a function of kernel thickness at $40^{\circ} \mathrm{C}, 50^{\circ} \mathrm{C}$, and $60^{\circ} \mathrm{C}$ for medium-grain cultivars CL 261 (a) and Jupiter (b). Each data point represents the drying rate of an individual rough rice kernel plotted against the corresponding kernel thickness when dried at the specified temperature.

width. Additionally, Banaszek and Siebenmorgen (1993) reported that the kernel width to thickness ratio affected $\mathrm{k}$, and that drying rate was more impacted by kernel thickness in long-grain cultivars than in medium-grain cultivars, and this impact was more pronounced at high Ts. It is well established that diffusivity increases as $\mathrm{T}$ increases ( $\mathrm{Lu}$ and Siebenmorgen, 1992), but it is expected that the increase in diffusivity would be similar for both medium- and longgrain cultivars. It was then reasoned that differences in the circumference of each kernel type may be responsible for the greater impact of kernel thickness on drying rates observed for long-grains. Given that kernel thickness of long-grain cultivars was similar to that of medium-grain cultivars, and because circumference impacts surface area, it was hypothesized that increasing thickness, increases the surface area proportionally more in long-grain than in medium-grain cultivars.

\section{EFFECT OF CULTIVAR ON DRYING RATES OF INDIVIDUAL KERNELS}

Figures $5 \mathrm{a}, 5 \mathrm{~b}$, and $5 \mathrm{c}$ show drying rate as a function of kernel thickness for long-grain cultivars, Wells, CL XL745, and $\mathrm{CL} 142$ at $40^{\circ} \mathrm{C}, 50^{\circ} \mathrm{C}$, and $60^{\circ} \mathrm{C}$, respectively. Figures $5 \mathrm{a}$ and $5 \mathrm{~b}$ show that there were no considerable drying rate differences due to cultivar at $40^{\circ} \mathrm{C}$ and $50^{\circ} \mathrm{C}$ across the kernel-thickness range. However, it appears there were differences in k for cultivars Wells, CL XL745 and CL 142 at $60^{\circ} \mathrm{C}$ and at low thickness levels (fig. 5c). Similar trends were observed for the medium-grains (data not shown). It was reasoned that these differences might be in part due to differences in kernel width among cultivars. For example, long-grain Wells, which had the least width, appeared to have the slowest drying rate. However, long-grain CL XL745, which had the greatest width, tended to have the greatest drying rate. Thus, width did not explain the trends observed. Because differences in drying rate among cultivars appear to be more pronounced at high $\mathrm{Ts}\left(60^{\circ} \mathrm{C}\right)$, it was reasoned that water diffusivity differences among cultivars may explain the drying rate differences in figure $5 \mathrm{c}$. There are several factors, such as the chemical composition of the rice kernel, which may affect water diffusivity inside rice kernels. Lu and Siebenmorgen (1992) and Prakash and Bingol (2011) reported diffusivity values for the endosperm, bran and hull of several rice cultivars and showed that the diffu- 
(a)
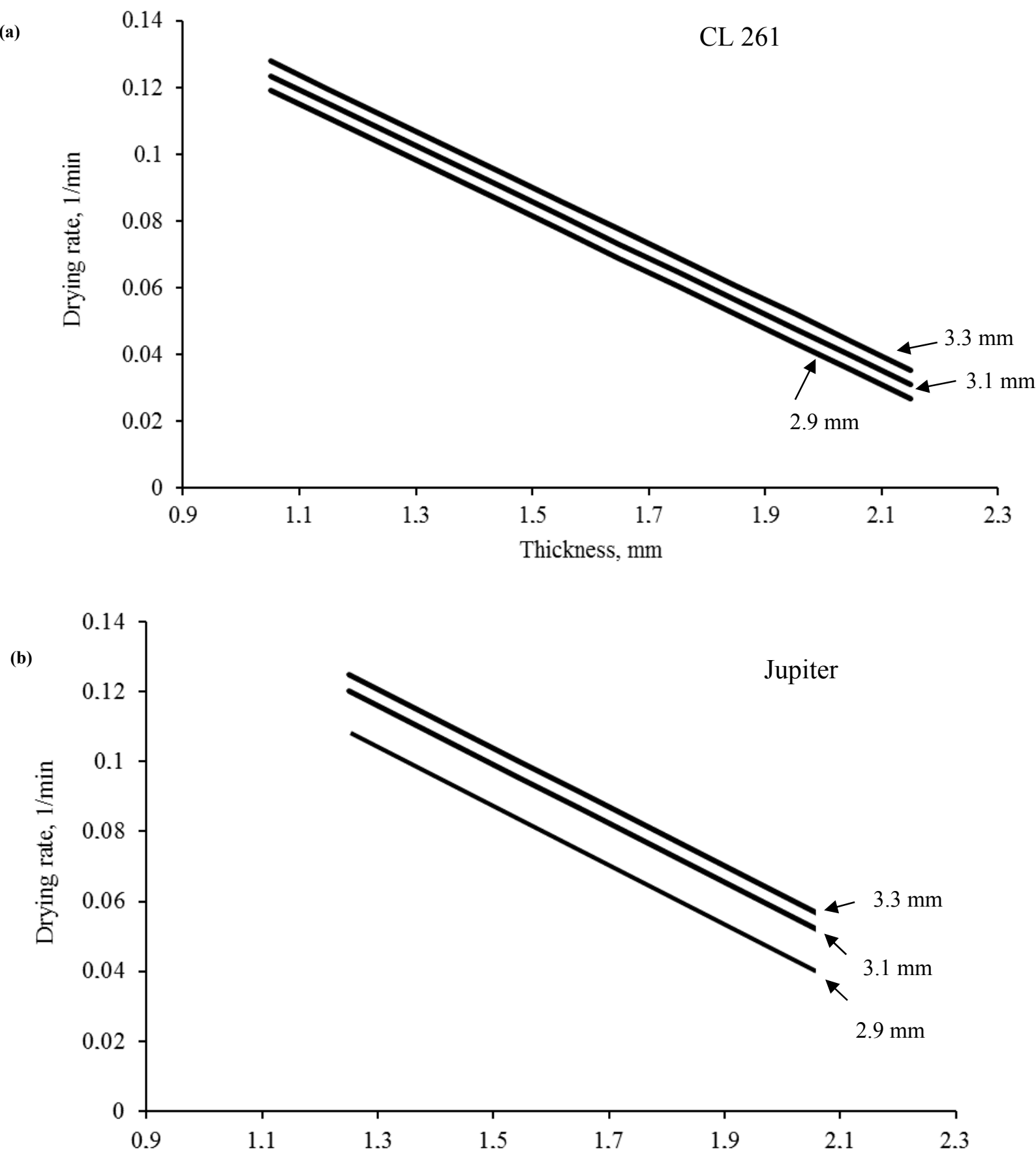

Thickness, mm

Figure 4. Drying rate (k, eq. 1) as a function of kernel thickness at width levels of 2.9, 3.1, and 3.4 mm for medium-grain cultivars CL 261 (a) and Jupiter (b). Curves were obtained using equation 3 for a drying temperature of $50^{\circ} \mathrm{C}$ and the three width levels specified.

sivity of the endosperm was greatest, followed by the diffusivity of the bran and then the hull. These differences in diffusivity values among rice components are reasons to be due to differences in chemical composition. In turn, the impact that rice cultivar might have on drying rates may be due to differences in proximate composition among cultivars. Table 1 shows the differences in proximate composition among the five rice cultivars used in this study including lipid content, protein content, and amylose content. 
(a)

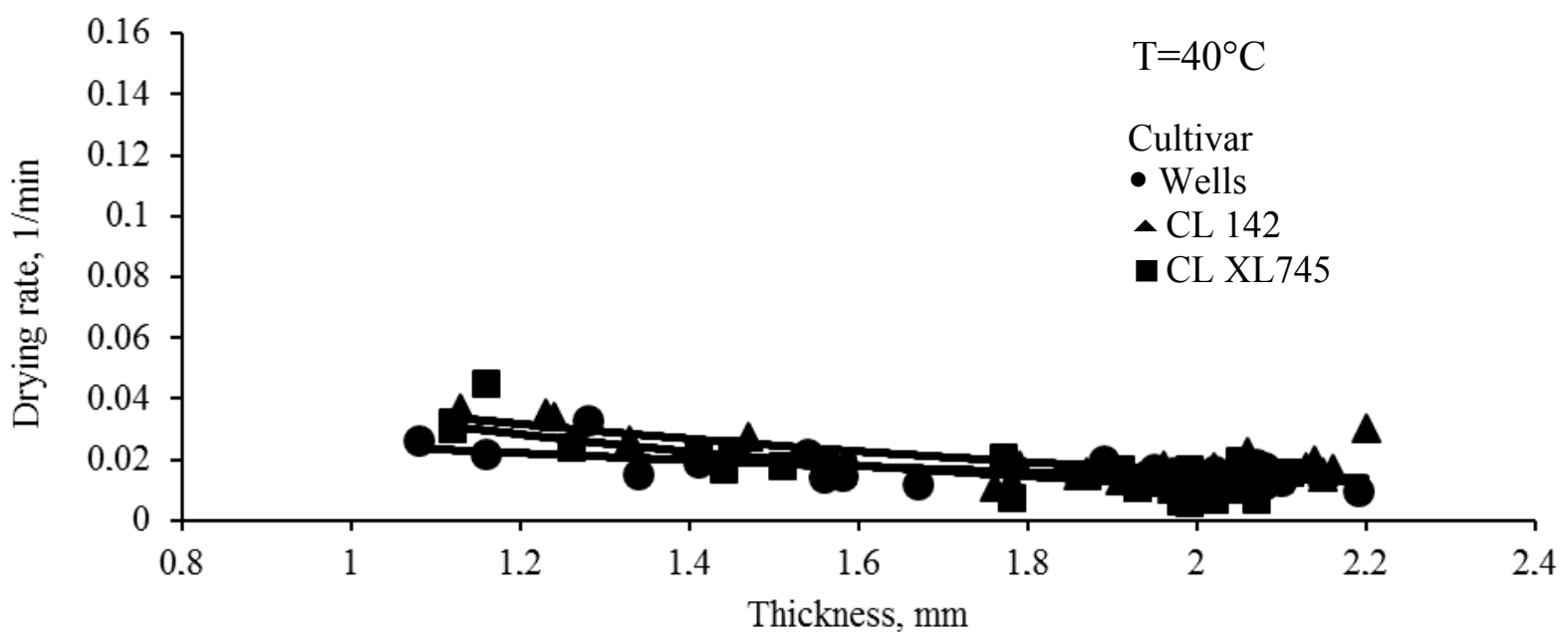

(b)

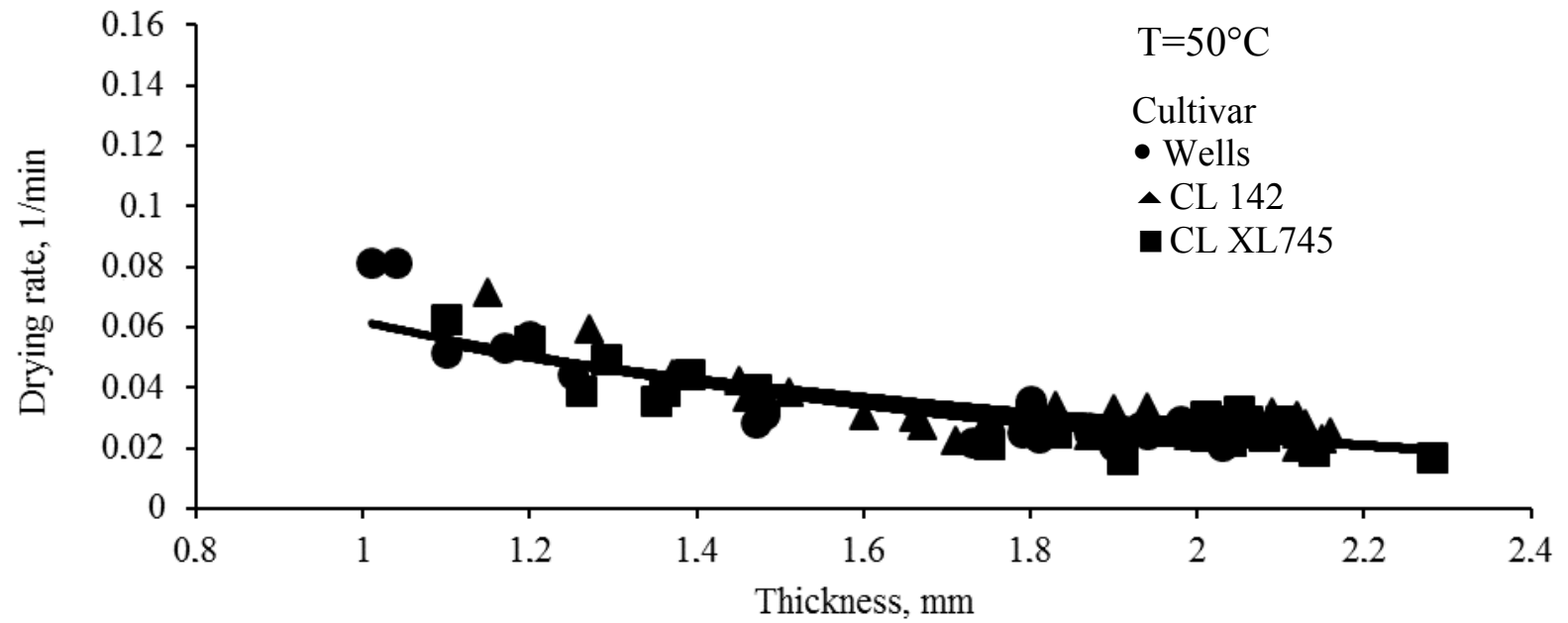

(c)

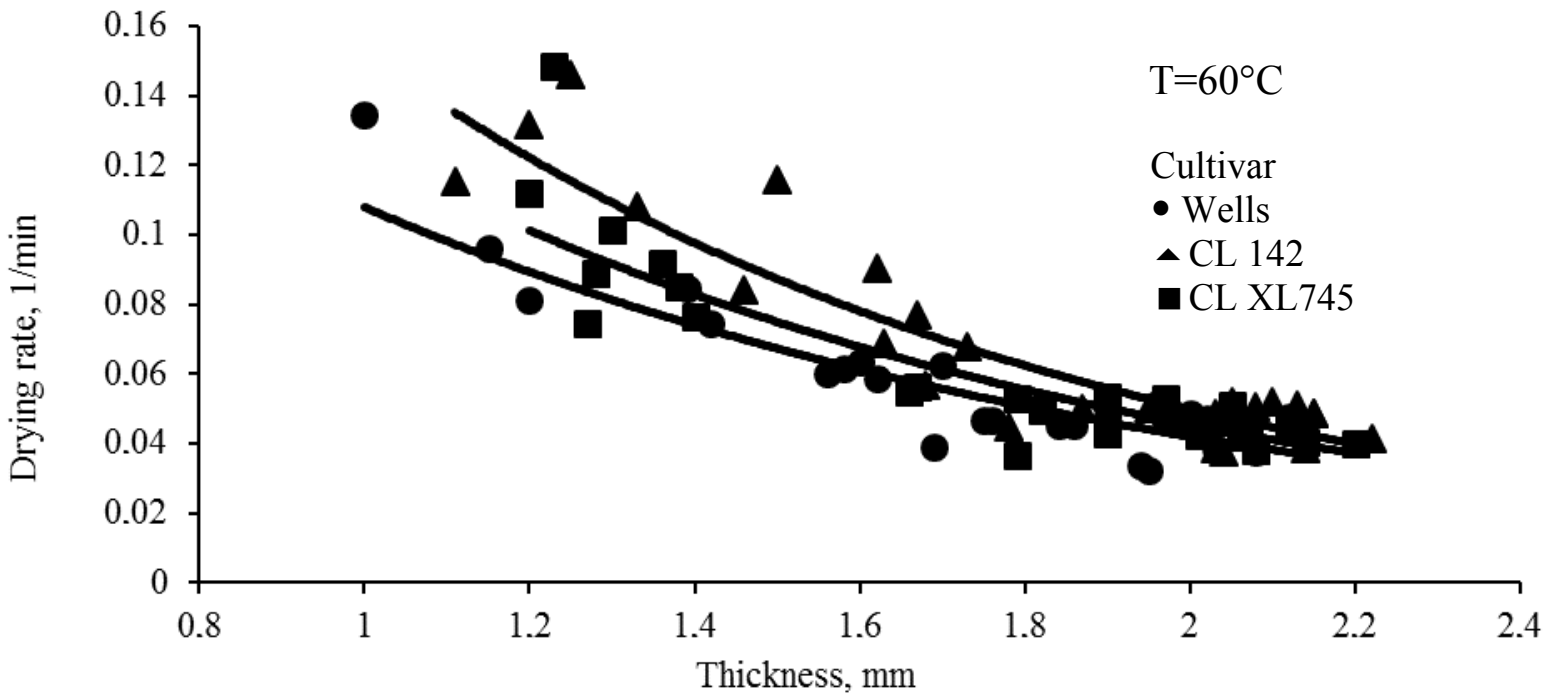

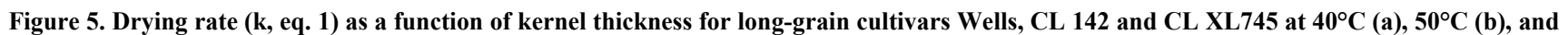
$60^{\circ} \mathrm{C}(\mathrm{c})$. Each data point represents drying rates of an individual rough rice kernel plotted against the corresponding thickness when dried at the specified temperature. 


\section{Conclusions}

The effect of kernel dimensions and drying air T on drying rates of individual rough rice kernels was assessed for five rice cultivars. In general, as kernel thickness decreased, drying rate increased. This effect became more pronounced as drying air $\mathrm{T}$ increased from $40^{\circ} \mathrm{C}$ to $60^{\circ} \mathrm{C}$. Furthermore, drying rate was more impacted by thickness in long-grain cultivars than in medium-grain cultivars, reasoned to be due to proportionally greater differences in the circumference and surface area of the kernel when thickness is varied in long-grains vs medium-grains. Additionally, drying rate increased as kernel width increased. Rice cultivar appeared to have an effect on drying rates at $60^{\circ} \mathrm{C}$ and low kernel thickness levels but there was no effect of cultivar at $40^{\circ} \mathrm{C}$ and $50^{\circ} \mathrm{C}$

To assess the applicability of these results at a commercial scale, the aggregate drying rates of single kernels should be validated with drying rates of bulk samples. This is important since the data collected in this study is intended to aid in the modelling of drying rates and fissure formation inside commercial driers.

\section{REFERENCES}

AACC International. (2010). Methods of analysis, 11th Ed. Methods 30-20.01. Available online only. St. Paul, MN: AACC Int.

AOAC. (1990). Official methods of analysis (15th ed.). Arlington, VA, : Association of Official Analytical Chemists.

ASABE Standards. (2009). Moisture relationships of plant based agricultural products. St. Joseph, MI: ASABE.

Banaszek, M. M., \& Siebenmorgen, T. J. (1993). Individual rice kernel drying curves. Trans. ASAE, 36(2), 521-528. http://dx.doi.org/10.13031/2013.28368

Bautista, R. C., \& Bekki, E. (1997). Gra fissures in rough rice drying: Differences in fissuring behavior of selected Japonica and Indica varieties. J. Japanese Soc. Agric. Machinery, 59(4), 97-108.

Chen, C., \& Wu, P. C. (2001). PH-Postharvest technology. J. Agric. Eng. Res., 80(1), 45-52. http://dx.doi.org/10.1006/jaer.2000.0677

Cihan, A., \& Ece, M. C. (2001). Liquid diffusion model for intermittent drying of rough rice. J. Food Eng., 49(4), 327-331. http://dx.doi.org/10.1016/S0260-8774(00)00230-2

Cnossen, A. G., \& Siebenmorgen, T. J. (2000). The glass transition temperature concept in rice drying and tempering: Effect on milling quality. Trans. ASAE, 43(6), 1661-1667. http://dx.doi.org/10.13031/2013.3066

Dong, R., Lu, Z., Liu, Z., Nishiyama, Y., \& Cao, W. (2009). Moisture distribution in a rice kernel during tempering drying. $J$. Food Eng., 91(1), 126-132. http://dx.doi.org/10.1016/j.jfoodeng.2008.08.012

Dung, N. V., Bowrey, R. G., \& Fowler, R. T. (1980). Variables affecting drying rate of paddy rice. Food Technology in Australia, 32(12), 604-606.

Fan, J., Siebenmorgen, T. J., \& Yang, W. (2000). A study of head rice yield reduction of long- and medium-grain rice varieties in relation to various harvest and drying conditions. Trans. ASAE, 43(6), 1709-1714. http://dx.doi.org/10.13031/2013.3072
Iguaz, A., San Martin, M. B., Mate, J. I., Fernandez, T., \& Virseda, P. (2003). Modelling effective moisture difusivity of rough rice (Lido cultivar) at low drying temperatures. J. Food Eng., 59(23), 253-258. http://dx.doi.org/10.1016/S0260-8774(02)00465-X

Jindal, V. K., \& Siebenmorgen, T. J. (1987). Effects of oven drying temperature and drying time on rough rice moisture content determination. Trans. ASAE, 30(4), 1185-1192. http://dx.doi.org/10.13031/2013.30542

Juliano, B. O. (1971). A simplified assay for milled-rice amylose. Cereal Sci. Today, 16(10), 334-340.

Kahveci, K., Cihan, A., \& Ece, M. C. (2003). Liquid diffusion model for drying a stack of rough rice. Int. J. Energy Res., 27(12), 1131-1143. http://dx.doi.org/10.1002/er.931

Lu, R., \& Siebenmorgen, T. J. (1992). Moisture diffusivity of longgrain rice components. Trans. ASAE, 35(6), 1955-1961. http://dx.doi.org/10.13031/2013.28822

Madhava, M., Rao, P. S., \& Goswami, T. K. (2001). Drying kinectics of paddy using thermogravimetric analysis. Drying Technol., 19(6), 1201-1210. http://dx.doi.org/10.1081/DRT100104815

Matsler, A. L., \& Siebenmorgen, T. J. (2005). Evaluation of operating conditions for surface lipid extraction from rice using a soxtec system. Cereal Chem. J., 82(3), 282-286. http://dx.doi.org/10.1094/CC-82-0282

Ondier, G. O., Siebenmorgen, T. J., \& Mauromoustakos, A. (2010). Low-temperature, low-relative humidity drying of rough rice. $J$. Food Eng., 100(3), 545-550. http://dx.doi.org/10.1016/j.jfoodeng.2010.05.004

Prakash, B., Bingol, G., \& Pan, Z. (2011). Moisture diffusivity in rice components during absorption and desorption. Drying Technol., 29(8), 939-945. http://dx.doi.org/10.1080/07373937.2011.561942

Schluterman, D. A., \& Siebenmorgen, T. J. (2007). Relating rough rice moisture content reduction and tempering duration to head rice yield reduction. Trans. ASABE, 50(1), 137-142. http://dx.doi.org/10.13031/2013.22385

Siebenmorgen, T. J., Yang, W., \& Sun, Z. (2004). Glass transition temperature of rice kernels determined by dynamic mechanical thermal analysis. Trans. ASAE, 47(3), 835-839. http://dx.doi.org/10.13031/2013.16080

Wang, C. Y., \& Singh, R. P. (1978). A single layer drying equation for rough rice. ASAE Paper No. 78-3001. St. Joseph, MI: ASAE.

Williams, V. R., Wu, W.-T., Tsai, H. Y., \& Bates, H. G. (1958). Rice starch, varietal differences in amylose content of rice starch. J. Agric. Food. Chem., 6(1), 47-48. http://dx.doi.org/10.1021/jf60083a009

Wu, 上., Yang, W., \& Jia, C. (2004). A three-dimensional numerical simulation of transient heat and mass transfer inside a single rice kernel during the drying process. Biosyst. Eng., 87(2) 191-200. http://dx.doi.org/10.1016/j.biosystemseng.2003.09.6u4

Yang, W., Jia, C. C., \& Howell, T. A. (2003a). Relationship of moisture content gradients and glass transition temperatures to head rice yield during cross-flow drying. Biosyst. Eng.. 86(2), 199-206. http://dx.doi.org/10.1016/S1537-5110(03 juv $129-6$

Yang, W., Jia, C. C., Siebenmorgen, T. J., Pan, Z., \& Cnossen, A. G. (2003b). Relationship of kernel moisture content gradients and glass transition temperatures to head rice yield. Biosyst. Eng., 85(4), 467-476. http://dx.doi.org/10.1016/S15375110(03)00091-6 